\title{
Performance Evaluation for Gas Production Units Based on ANP
}

\author{
Jianhong Gou ${ }^{1,2}$, Anqi $\mathrm{Li}^{3}$, Zhibin Liu ${ }^{1}$, Xinhai Kong ${ }^{4}$, Haohan Liu ${ }^{1,5^{*}}$ \\ ${ }^{1}$ School of Graduate, Southwest Petroleum University, Chengdu, China \\ ${ }^{2}$ The No. 1 Gas Production Plant, PetroChina Changqing Oilfield Company, Yinchuan, China \\ ${ }^{3}$ PetroChina Changqing Oilfield Company, Xi'an, China \\ ${ }^{4}$ Department of Petroleum Engineering, Guang'an Vocational \& Technical College, Guang'an, China \\ ${ }^{5}$ Sichuan College of Architectural Technology, Deyang, China, \\ Email: *tsinghua616@163.com
}

Received August 25, 2013; revised September 25, 2013; accepted October 5, 2013

Copyright (C) 2013 Jianhong Gou et al. This is an open access article distributed under the Creative Commons Attribution License, which permits unrestricted use, distribution, and reproduction in any medium, provided the original work is properly cited.

\begin{abstract}
In view of the existing situation of gas field development, one kind of method to evaluate the production performance of gas production units (GPUs) was presented in this paper. Among the commonly used indicators of gas field development, we select 11 indicators from the three aspects of production task, gas reservoir management, and production technology. According to the principle of analytic network process (ANP), this paper introduced one kind of new method to get the weights of indicators. By means of the method of TOPSIS, it is easy to obtain the rankings for all the GPUs through calculating the weighted Euclidean distance between each GPU and the positive or negative ideal point. This evaluation method could constantly improve the management level of gas production units and deepen the delicacy management of gas field development.
\end{abstract}

Keywords: Gas Production Unit (GPU); Performance Evaluation; Analytic Network Process (ANP); TOPSIS

\section{Introduction}

The oil and gas field companies mostly take the management concept of "Benchmarking" during the process of gas field development [1]. According to the dynamic analysis of gas reservoir development, the technical section provides a kind of development scheme and sets some feasible goals that should be achieved. And the gas production units (GPUs) must achieve the production goals in accordance with the development requirements [2]. Currently, the development department in the process of gas field development evaluates the production performance of GPUs based on their own statistics data and the assessment results calculated by themselves [3]. It means that the evaluation accuracy is not high enough and the crosswise contrast is not enough. In order to make the development department accurate and timely, and grasp the current situation of development and management of GPUs, it needs to establish a relatively perfect evaluation system to really respond to the management level, efficiency, and development effect of GPUs,

\footnotetext{
"Corresponding author.
}

promoting the delicacy management of gas field development. In this paper, we first present the evaluation indicators and their computing methods. In order to reasonably decide the weight of each indicator, this method of ANP is introduced. Next, we introduce the method of TOPSIS to decide the comprehensive ranking of GPUs and use the Euclidean distance to describe the proximity between two GPUs.

\section{Use Evaluation Indicators and Their Computing Methods}

Through the analysis, the production performance evaluation indicators of GPU are divided into three aspects of production task, gas reservoir management, and production technology [1-5] (see Figure 1), including 11 indicators in the following.

\subsection{Production Task}

The production task [4,5], denoted as $B_{1}$, contains the completion rate of gas production $\left(C_{11}\right)$, the completion rate of water injection $\left(C_{12}\right)$, and the completion rate of 


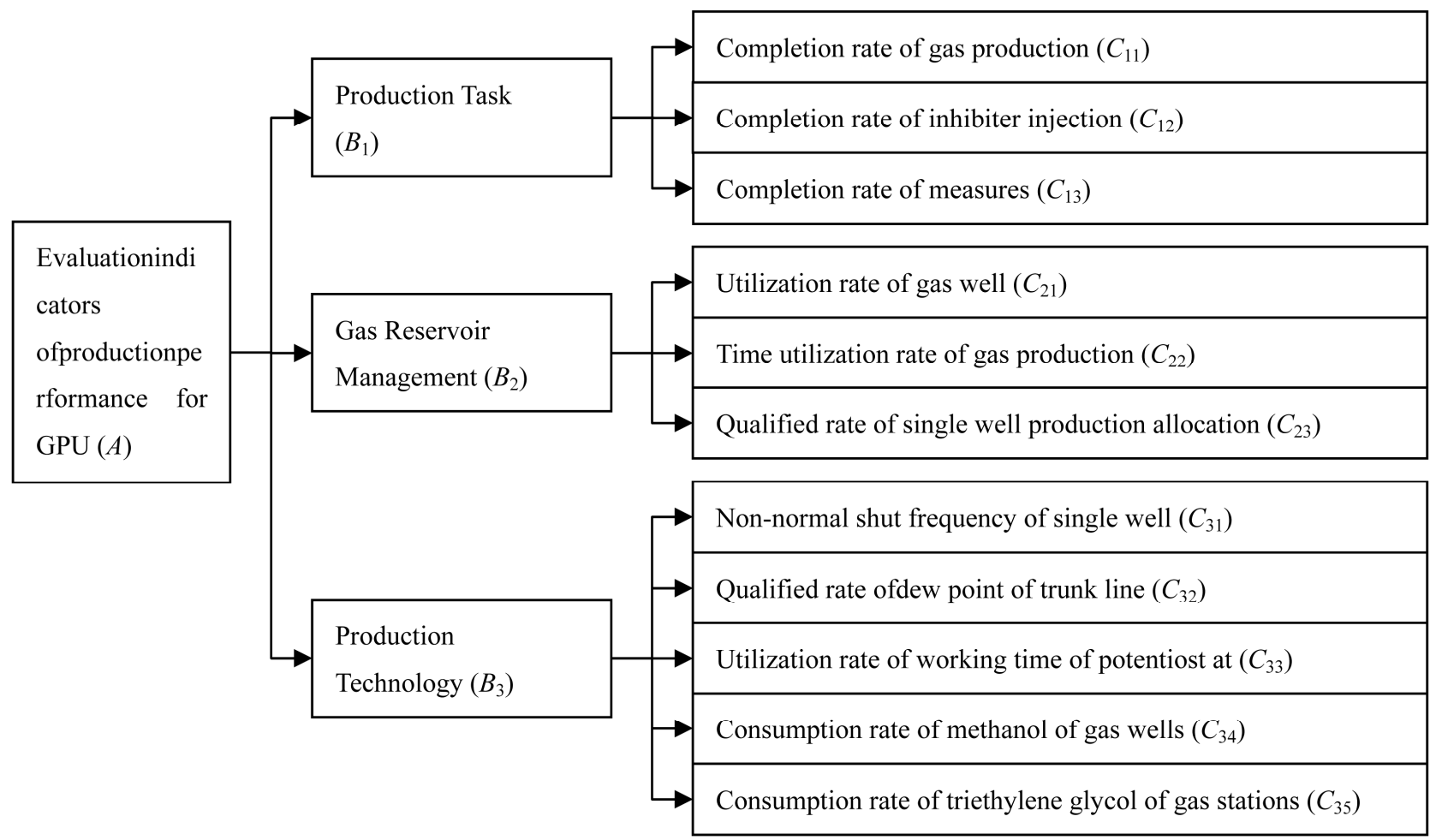

Figure 1. Hierarchical relationship of the evaluation indicators.

Measures $\left(C_{13}\right)$,.

(1) Completion rate of gas production.

$$
C_{11}=v / v_{0} \times 100 \% \text {, }
$$

where $v$ is the actual gas production, $v_{0}$ is the planned gas output, unit: $\mathrm{m}^{3}$.

(2) Completion rate of inhibiter injection.

$$
C_{12}=q / q_{0} \times 100 \%,
$$

where $q$ is the actual amount of filling, $q_{0}$ is the planned amount of filling, unit: "tons".

(3) Completion rate of measures.

$$
C_{13}=N / N_{0} \times 100 \%,
$$

where $N$ is the actual number of measures, $N_{0}$ is the arranged number of measures, unit: "times".

\subsection{Gas Reservoir Management}

The gas reservoir development [6,7], denoted as $B_{2}$, contains the utilization rate of gas well $\left(C_{21}\right)$, the time utilization rate of gas production $\left(C_{22}\right)$ and the qualified rate of single well production allocation $\left(C_{23}\right)$.

(1) Utilization rate of gas well.

$$
C_{21}=n / n_{0} \times 100 \%,
$$

where $n$ is the actual number of open wells, $n_{0}$ is the total number of gas wells.

(2) Time utilization rate of gas production.

$$
C_{22}=t / t_{0} \times 100 \%,
$$

where $t$ is the actual time of gas production, $t_{0}$ is the calendar time of gas production, unit: day.

(3) Qualified rate of single well production allocation.

$$
C_{23}=m / n \times 100 \%,
$$

where $m$ is the number of qualified wells, $n$ is the actual number of open wells.

\subsection{Production Technology}

The gas production technology [8-12], denoted as $B_{3}$, contains the non-normal shut frequency of single well $\left(C_{31}\right)$, the qualified rate of dew point of trunk line $\left(C_{32}\right)$, the utilization rate of working time of potentiostat $\left(C_{33}\right)$, the consumption rate of methanol of gas wells $\left(C_{34}\right)$ and the consumption rate of triethylene glycol of gas stations $\left(C_{35}\right)$.

(1) Non-normal shut frequency of single well.

$$
C_{31}=L / n \times 100 \%,
$$

where $L$ is the number of non-normal shut, $n$ is the actual number of open wells, unit: times per one well.

(2) Qualified rate of dew point of trunk line.

$$
C_{32}=c / c_{0} \times 100 \%,
$$

where $c$ is the qualified number of monitored dew points, $c_{0}$ is the total number of monitored dew points, 
unit: times.

(3) Utilization rate of working time of potentiostat.

$$
C_{33}=T / T_{0} \times 100 \%,
$$

where $T$ is the actual working time of potentiostat, $T_{0}$ is the calendar working time of potentiostat, unit: hour.

(4) Consumption rate of methanol of gas wells.

$$
C_{34}=Q / Q_{0} \times 100 \%,
$$

where $Q$ is the actual consumption of methanol, $Q_{0}$ is the total annual budget, unit: tons.

(5) Consumption rate of triethylene glycol of gas stations.

$$
C_{35}=V / v \times 100 \%,
$$

where $V$ is the consumption of triethylene glycol, unit: kg; $v$ is the gas production, unit: $\mathrm{m}^{3}$.

\section{Production Performance Evaluation for Gas Reservoir Management Units}

Assume that there are $m$ GPUs and $n$ evaluation indicators, the decision data matrix is denote $\mathrm{d}$ by $X=\left(x_{i j}\right)_{m \times n}$. According to the method of TOPSIS, the comprehensive ranking procedure for GPUs consists of the following steps.

Step 1: Standardize the decision data matrix. The standardized decision data matrix is denoted by $Y=\left(y_{i j}\right)_{m \times n}$, and the transformation formula are given in the following.

(a) When the $j$ th indicator is the benefit type,

$$
y_{i j}=\frac{x_{i j}-\min _{i}\left\{x_{i j}\right\}}{\max _{i}\left\{x_{i j}\right\}-\min _{i}\left\{x_{i j}\right\}}
$$

(b) When the $j$ th indicator is the cost type,

$$
y_{i j}=\frac{\max _{i}\left\{x_{i j}\right\}-x_{i j}}{\max _{i}\left\{x_{i j}\right\}-\min _{i}\left\{x_{i j}\right\}}
$$

(c) When the $j$ th is the target type,

$$
y_{i j}=1-\frac{\left|x_{i j}-x_{0}\right|}{\max \left\{\max _{i}\left\{x_{i j}\right\}-x_{0}, x_{0}-\min _{i}\left\{x_{i j}\right\}\right\}}
$$

Step 2: Determine the weights of indicators. The weight vector $\omega=\left(\omega_{1}, \omega_{2}, \cdots, \omega_{n}\right)$ can be obtained by ANP. Further more, we could calculate the weighted decision matrix $Z=\left(z_{i j}\right)_{m \times n}$, where $z_{i j}=w_{j} \cdot y_{i j}$.

Step 3: Determine the positive ideal vector and the negative ideal vector. Respectively, denoted by $z^{+}=\left(z_{1}^{+}, z_{2}^{+}, \cdots, z_{n}^{+}\right)$and $z^{-}=\left(z_{1}^{-}, z_{2}^{-}, \cdots, z_{n}^{-}\right)$, where $z_{j}^{+}=\max _{i}\left\{z_{i j}\right\}$ and $z_{j}^{-}=\min \left\{z_{i j}\right\}$.

Step ${ }^{i}$ 4: Calculate the Euclidean distance from the positive ideal vector and the negative ideal vector. The
Euclidean distance between the $i$-th RMU and the positive ideal vector is denoted by

$$
d_{i}^{+}=\sqrt{\sum_{k=1}^{n}\left(z_{i k}-z_{k}^{+}\right)^{2}}
$$

The Euclidean distance between the $i$-th RMU and the negative ideal vector is denoted by

$$
d_{i}^{-}=\sqrt{\sum_{k=1}^{n}\left(z_{i k}-z_{k}^{-}\right)^{2}}
$$

Step 5: Calculate the relative closeness to the positive ideal vector. The relative closeness can be defined as

$$
f_{i}^{*}=d_{i}^{-} /\left(d_{i}^{-}+d_{i}^{+}\right), i=1,2, \cdots, m
$$

Step 6: Decide the ranking according to the value of $f_{i}^{*}$. The bigger the closeness shows the better the ranking.

\section{Example Analysis}

The statistical data of 7 gas production units (GPUs) of an oilfield in the year of 2012 are listed in Table 1. According to the basic data in Table 1, we could obtain the evaluation results.

Setp 1: Build the network structure of the evaluation indicators (see Figure 2).

Setp 2: Calculation the weights of the evaluation indicators. All judgment matrixes are as follows:

All calculations are done by the Super Decisions software. From the limit matrix, we can obtain the weights of all the evaluation indicators listed in the following.

$$
\begin{aligned}
& c_{11}=0.44173 ; c_{12}=0.11055 ; c_{13}=0.26540 ; \\
& c_{21}=0.05395 ; c_{22}=0.03732 ; c_{23}=0.01015 ; \\
& c_{31}=0.03642 ; c_{32}=0.00507 ; c_{33}=0.00716 ; \\
& c_{34}=0.02944 ; c_{35}=0.00282
\end{aligned}
$$

Step 3: Production performance evaluation for GPUs.

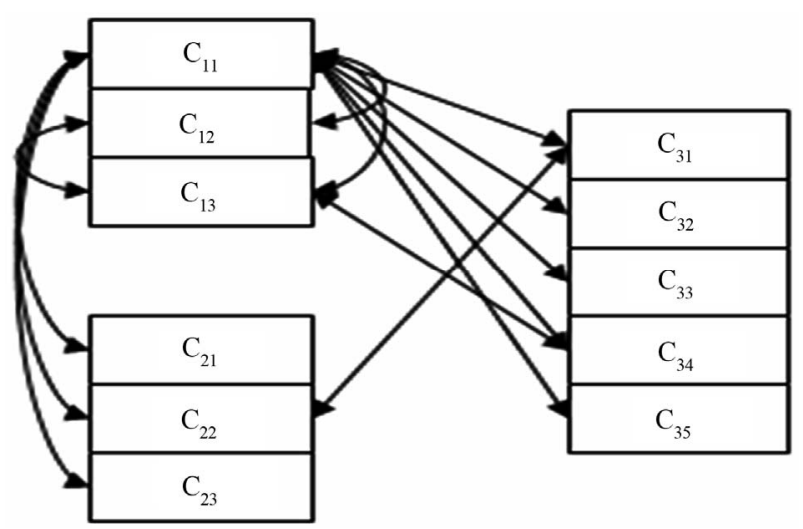

Figure 2. The network structure of the evaluation indicators. 
Table 1. The statistical data of 7 GPUs in 2012.

\begin{tabular}{ccccccccccccc}
\hline GPUs & $C_{11}$ & $C_{12}$ & $C_{13}$ & $C_{21}$ & $C_{22}$ & $C_{23}$ & $C_{31}$ & $C_{32}$ & $C_{33}$ & $C_{34}$ & $C_{35}$ \\
\hline 1 & 0.92 & 0.929 & 0.98 & 0.989 & 0.87 & 0.885 & 0.239 & 0.92 & 0.95 & 1.1038 & 0.36 \\
2 & 0.93 & 0.786 & 0.97 & 0.964 & 0.88 & 0.878 & 0.196 & 0.95 & 0.98 & 1.0383 & 0.22 \\
3 & 0.99 & 0.667 & 0.98 & 0.977 & 0.86 & 0.986 & 0.345 & 0.90 & 0.99 & 1.0451 & 0.32 \\
4 & 0.92 & 0.857 & 0.99 & 0.912 & 0.75 & 0.851 & 0.126 & 0.88 & 0.97 & 1.0369 & 0.35 \\
5 & 0.93 & 1.000 & 0.97 & 0.879 & 0.64 & 0.975 & 0.360 & 0.98 & 0.96 & 0.9844 & 0.34 \\
6 & 0.89 & 1.000 & 0.97 & 0.968 & 0.70 & 0.906 & 0.016 & 0.96 & 0.98 & 0.9732 & 0.47 \\
7 & 0.78 & 0.793 & 0.95 & 0.892 & 0.82 & 0.824 & 0.514 & 0.85 & 0.94 & 1.0184 & 0.22 \\
\hline
\end{tabular}

\section{Conclusions}

1. A relatively perfect evaluation method is established to really respond to the management level, efficiency, and development effect of GPUs, which can promote the delicacy management of gas field development.

2. Some practically feasible evaluation indicators and their computing methods are firstly presented through analyzing the actual situation in the process of gas field development.

3. We can decide the comprehensive rankings of GPUs through calculating the weighted Euclidean distance between every GPU and the positive or negative ideal RMU by means of the method of TOPSIS.

4. A practical example is illustrated to explain the feasibility of this method.

\section{REFERENCES}

[1] J. Y. Liu, "Geological Foundation of Oil and Gas Field Development,” Petroleum Industry Press, Beijing, 2006.

[2] Y. C. Li, "The Technology of Petroleum Production," 2nd Edition, Petroleum Industry Press, Beijing, 2009.

[3] P. T. Geoffrey, "Oil and Gas: A Practical Handbook," Globe Law and Business, London, 2009.

[4] N. Ezekwe, "Petroleum Reservoir Engineering Practice," Prentice Hall, Upper Saddle River, 2010.

[5] C. L. Li, "Fundamentals of Reservoir Engineering (Second edition)”, Petroleum Industry Press, Beijing, 2011.
[6] K. Joshi and R. Kant, "Decision Making in Effective Supply Chain Collaboration: A Fuzzy AHP Approach,” International Journal of Decision Sciences, Risk and Management, Vol. 4, No. 3-4, 2012, pp. 197-261.

[7] H.-W. Yang and K.-F. Chang, "Combining Means-End Chain and Fuzzy ANP to Explore Customers' Decision Process in Selecting Bundles," International Journal of Information Management, Vol. 32, No. 1, 2012, pp. 381395.

[8] M. L. Tseng, Y. H. Lin, A. S. F. Chiu and J. C. H. Liao, "Using FANP Approach on Selection of Competitive Priorities Based on Cleaner Production Implementation: A Case Study in PCB Manufacturer, Taiwan," Clean Technologies and Environmental Policy, Vol. 10, No. 1, 2008, pp. 17-29. http://dx.doi.org/10.1007/s10098-007-0109-4

[9] H.-Y. Kang, A. H. I. Lee and C.-Y. Yang, “A Fuzzy ANP Model for Supplier Selection as Applied to IC Packaging,” Journal of Intelligent Manufacturing, Vol. 23, No. 1, 2012, pp. 1477-1488.

[10] F. Kong and H. Y. Liu, “Applying Fuzzy Analytic Hierarchy Process to Evaluate Success Factors of E-Commerce,” International Journal of Information and Systems Sciences, Vol. 1, No. 3-4, 2005, pp. 406-412.

[11] H. C. Sun, G. Y. Xu and P. Tian, "Design Alternatives Evaluation of Emergency Bridge by Applying Analytic Network Process," Systems Engineering-Theory \& Practice, Vol. 27, No. 3, 2007, pp. 63-70. http://dx.doi.org/10.1016/S1874-8651(08)60025-3

[12] T. L. Saaty and L. G. Vargas, "Decision Making with the Analytic Network Process,” Springer, 2010. 